UDK: 655.3.022:004.9

DOI: https://doi.org/10.24867/03EF02Djukic

\title{
ISPITIVANJE KVALITETA OTISAKA DOBIJENIH NA MAŠINAMA DURST P10 I HP LATEX R2000
}

\section{TESTING PRINT QUALITY ON DURST P10 AND HP LATEX R2000 MACHINES}

\author{
Maja Đukić, Nemanja Kašiković, Rastko Milošević, Fakultet tehničkih nauka, Novi Sad
}

\section{Oblast - GRAFIČKO INŽENJERSTVO I DIZAJN}

Kratak sadržaj - U okviru rada predstavljena su istraživanja iz oblasti digitalne štampe. Štampanje je vršeno na 5 različitih podloga koje su štampane na dve različite mašine i to na Durst P10 i HP Latex R2000. Istraživanja su zasnovana na skeniranju uzoraka, merenju spektrofotometrijskih vrednosti, trljanju uzoraka, a zatim analizi dobijenih rezultata na osnovu kojih je ustanovljena otpornost otiska na trljanje u zavisnosti od podloge. U radu je vršena $i$ vizuelna analiza uzoraka.

Ključne reči: digitalna štampa, ink jet, trljanje, kontrola kvaliteta, analiza.

Abstract - The research conducted within this master thesis stems from the field of digital printing. The printing was done on 5 different substrates printed on two different machines, i.e. the Durst P10, and the HP Latex R2000. The research is based on sample scanning, measurement of spectrophotometric values, processing (rubbing) of samples, and finally the analysis of the obtained results which show the resistance of the print to rubbing, depending on the substrate. Furthermore, the thesis also included a visual analysis of the samples.

Keywords: digital printing, ink jet, rubbing, quality control, analysis.

\section{UVOD}

Digitalna štampa je novija oblast štamparskih tehnologija koja je izazvala niz značajnih promena pogotovo u procesima gradnje štamparskih mašina, kao i u njihovom okruženju. Digitalna štampa podrazumeva štamparsku sliku koja do ulaska u štamparsku mašinu ostane u digitalnoj formi i tek u mašini ponovo bude sastavljena $u$ analognu štamparsku sliku. Samo ako se materijal štampa elementima za nanošenje, dakle bez štamparske forme, odnosno sa virtuelnom - imaginarnom štamparskom formom, onda se i ovaj proces odvija digitalno [1].

Kada je u pitanju digitalna štampa, treba imati na umu da ona ima mnogo prednosti u odnosu na ofset štampu, osim rokova isporuke. U principu, digitalna štampa je finansijski povoljnija nego ofset kod malih tiraža, te podrazumeva kvalitetnu štampu i relativno brzu izradu, koja naravno zavisi od tiraža koji želite. Posebnu prednost koju ima digitalna štampa u odnosu na standardnu ofset štampu jeste mogućnost personalizacije, ali i mogućnost štampe u slučaju kada je potrebno menjati i prilagođavati podatke

\section{NAPOMENA:}

Ovaj rad proistekao je iz master rada čiji mentor je bio dr Nemanja Kašiković, van. prof. nakon određenog broja primeraka, kao što je slučaj sa recimo štampanjem ulaznica, koje sadrže bar kodove ili štampanja kartica za nagradne igre [2].

Najznačajnija tehnika digitalne štampe je ink jet štampa. Pošto ova tehnika ima svakim danom sve veću zastupljenost, veliki broj proizvođača se bavi njome. Upravo zbog toga se na tržištu nalazi veliki broj grafičkih sistema koji mogu da daju različit kvalitet otisaka, kao i njegovu postojanost na različite uticaje.

$\mathrm{Na}$ osnovu svega gore pomenutog, postavljen je cilj da se ispita kvalitet otisaka dobijenih na grafičkim sistemima Durst P10 i HP Latex R2000, kao i postojanost odštampanih uzoraka na proces trljanja.

\section{METOD IZVOĐENJA EKSPERIMENTA}

Pre samog izvođenja eksperimenta, kreirana je test karta, prikazana na slici 1. Odštampana je na pet različitih materijala u štampariji NS Plakat na mašini Durst P10 i na Međunarodnom sajmu grafičke, papirne i kreativne industrije - GRAFIMA na mašini HP Latex R2000. To bi značilo da se izvođenje eksperimenta odvijalo na 10 uzoraka.
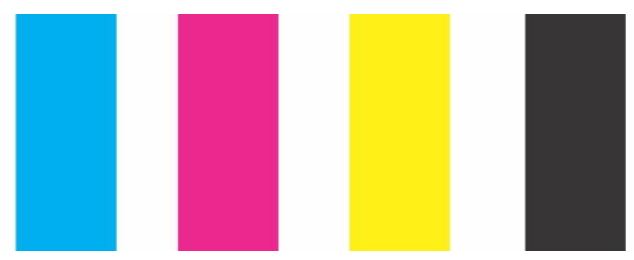

Slika 1. Izgled odštampane test trake

Materijali koji su korišćeni u eksperimentu su: 1. Papir $250 \mathrm{~g} / \mathrm{m}^{2} 2$. Troslojni karton 3. Forex $3 \mathrm{~mm} 4$. Akyplac 3 $\mathrm{mm}$ 5. Beli pleksiglas

Pomoću spektrofotometrijskog uređaja SpectroDens (merna geometrija $0 / 45^{\circ}$; standardni posmatrač $2^{\circ}$; standardno osvetljenje D50; tolerancija greške 0,3) uzorci nakon štampe su analizirani.

Nakon toga su analizirani uzorci izloženi ciklusima trljanja (3x). Za tu svrhu je korišćen je uređaj Testex TF411 koji je prikazan na slici 2. Broj ponavljanja za isti uzorak zavisi od materijala koji se testira i iznosio je za 1. Papir $250 \mathrm{~g} / \mathrm{m}^{2}$ (150 puta po svakom ciklusu), 2. Troslojni karton (100 puta po svakom ciklusu), 3. Forex $3 \mathrm{~mm} \mathrm{(50}$ puta po svakom ciklusu), 4. Akyplac $3 \mathrm{~mm}$ (100 po svakom ciklusu), 5. Beli pleksiglas (100 puta po svakom ciklusu). 


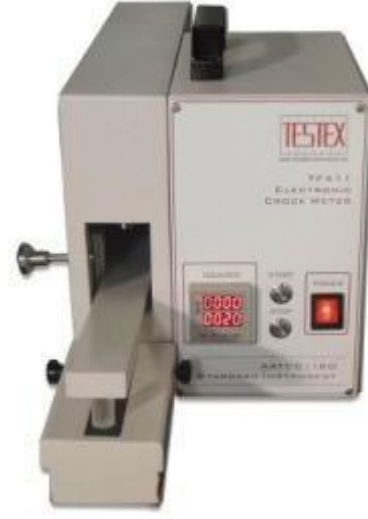

Slika 2. Testex TF411

Nakon trljanja uzoraka prisupljeno je njihovom skeniranju i pretvaranju u digitalne datoteke pomoću uređaja CanoScan 5600F. Uzorci su potom mereni ponovu pomoću uređaja SpectroDens i na osnovu tih merenja je određena razlika boje između uzoraka pre i posle izlaganja procesu trljanja.

\section{REZULTATI I DISKUSIJA}

Kao što je rečeno, svaka podloga je prošla tri ciklusa trljanja i to određen broj za svaki materijal. U nastavku je predstavljeno poređenje postojanosti boje na materijalima, odnosno razlika između boja pre trljanja i nakon svakog sledećeg trljanja.

Na graficima 1 do 8 je prikazano kako se CIE Lab koordinate odštampanih uzoraka menjaju pod uticajem trljanja

$$
\text { 1.merenje 2.merenje } \quad \text { 3.merenje } 4 \text {-merenje }
$$

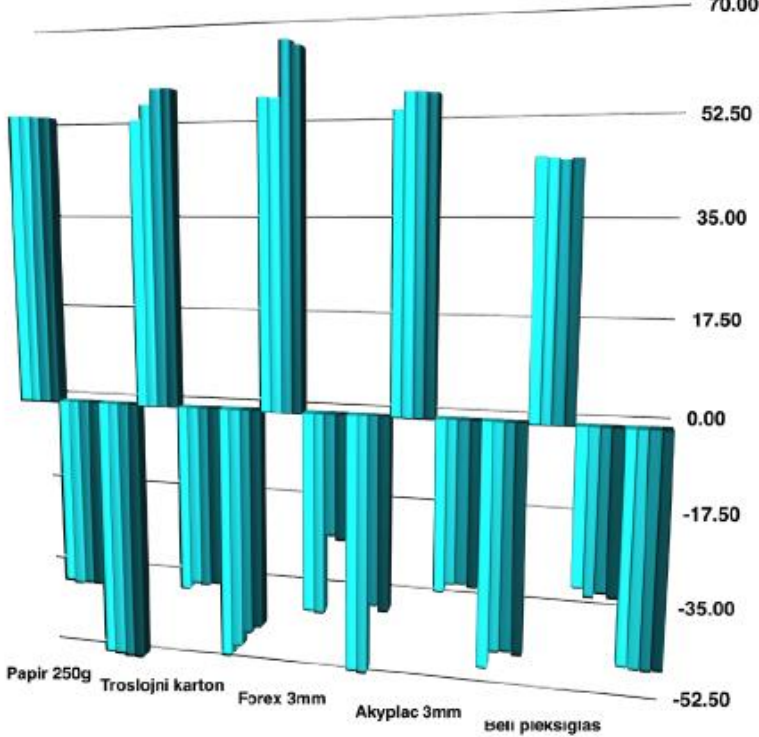

Grafik 1. Prikaz CIE Lab srednje vrednosti za cijan na mašini Durst P10

Prilikom merenja razlike u boji, dobijaju se vrednosti koje ukazuju koliko se boja skida nakon svakog ciklusa trljanja. Samim tim se može zaključiti koliko su boje postojane na određenom materijalu. $U$ ovom eksperimentu su se upoređivale vrednosti pre trljanja i posle prvog trljanja, pre trljana i posle drugog trljanja i pre trljanja i posle trećeg trljanja. Dobijene vrednosti prikazane su u nastavku, posebno za svaki materijal i boju.
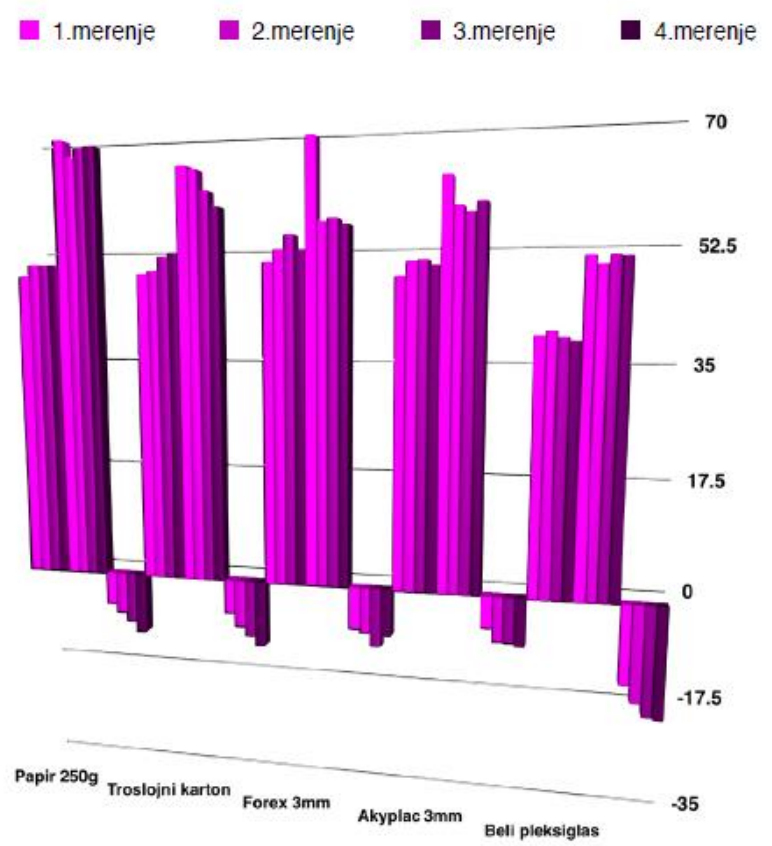

Grafik 2. Prikaz CIE Lab srednje vrednosti za magentu na mašini Durst P10

1.merenje $\quad$ 2.merenje $\quad$ 3.merenje $\quad$ 4.merenje

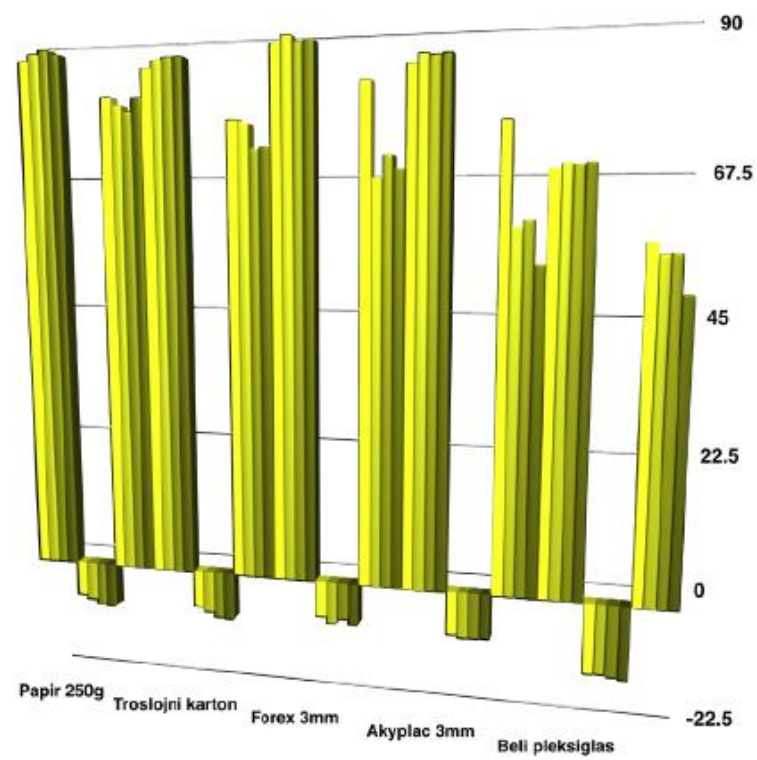

Grafik 3. Prikaz CIE Lab srednje vrednosti za žutu na mašini Durst P10

Prilikom upoređivanja razlika u boji na materijalu Papir $250 \mathrm{~g} / \mathrm{m}^{2}$, može se zaključiti sledeće:

Cijan - razlika se ne može primetiti.

Magenta - Papir $250 \mathrm{~g} / \mathrm{m}^{2}$ odštampan na mašini Durst P10 ima primetnu razliku, dok na mašini HP Latex R2000, razlika se ne može primetiti.

Žuta - Papir $250 \mathrm{~g} / \mathrm{m}^{2}$ odštampan na mašini Durst P10 ima veoma malu razliku, dok na mašini HP Latex R2000, razlika se ne može primetiti.

Crna - Razlika je primetna, kada su u pitanju obe mašine. 


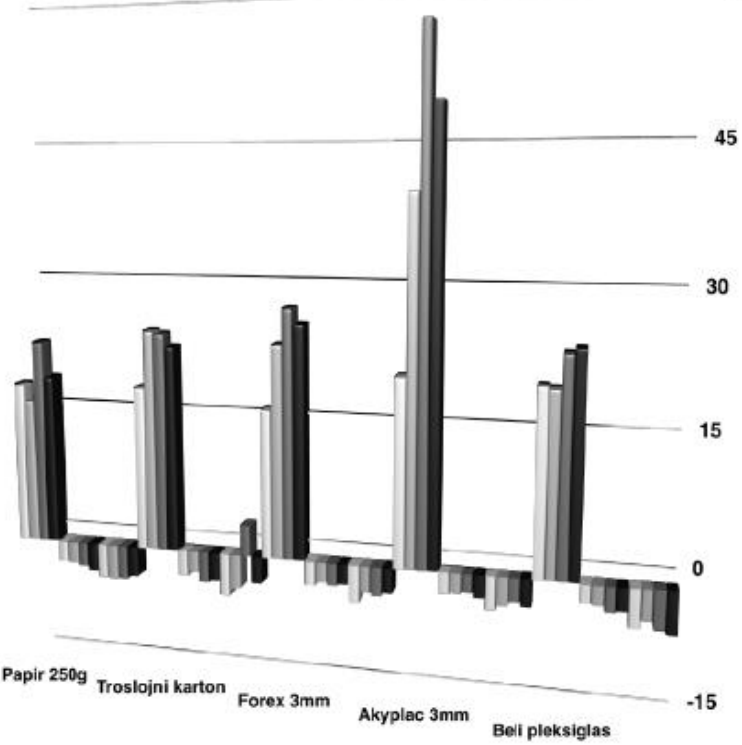

Grafik 4. Prikaz CIE Lab srednje vrednosti za crnu na mašini Durst P10

1.merenje $\quad$ 2.merenje $\quad$ 3.merenje $\quad$ 4.merenje

60

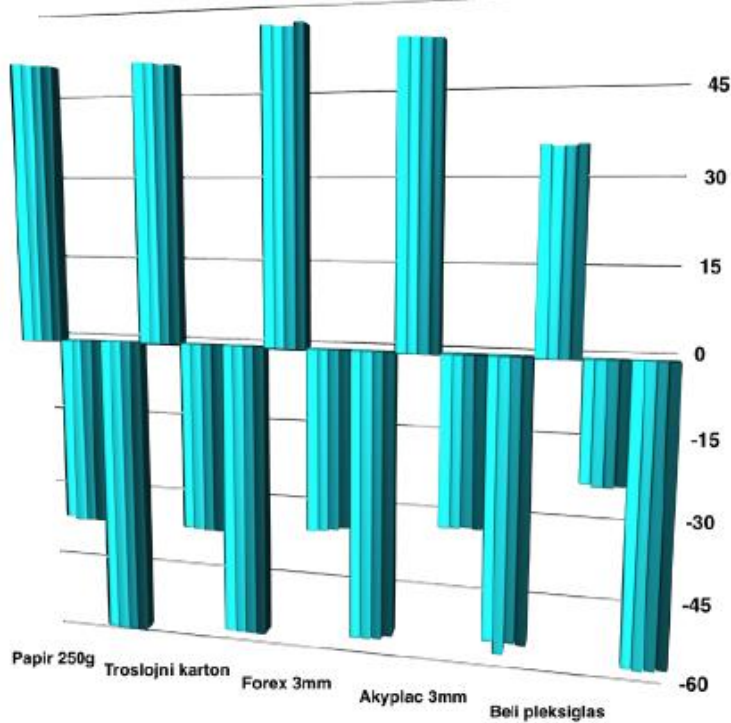

Grafik 5. Prikaz CIE Lab srednje vrednosti za cijan na mašini HP Latex R2000

Prilikom upoređivanja razlika u boji na materijalu Troslojni karton, može se zaključiti sledeće:

Cijan - Troslojni karton odštampan na mašini Durst P10 nakon prvog trljanja ima primetnu razliku, dok je nakon drugog i trećeg trljanja krupna razlika. Kada je u pitanju HP Latex R2000, razlika se ne može primetiti.

Magenta -Troslojni karton odštampan na mašini Durst P10 ima veoma malu razliku nakon prvog trljanja, nakon drugog trljannja srednju, a nakon trećeg krupnu razliku. Troslojni karton koji je odštampan na mašini HP Latex R2000, razlika se ne može primetiti.
Žuta - Troslojni karton odštampan na mašini Durst P10nema uočljivu razliku nakon prvog trljanja, dok nakon drugog i trećeg ima malu razliku. Kada je u pitanju mašina HP Latex R2000, razlika se ne može primetiti.

Crna - Razlika je krupna kada se radi o Troslojnom kartonu koji je odštampan na mašini Durst P10, a kada je u pitanju mašina HP Latex R2000, razlika je srednja i samim tim primetna golim okom.
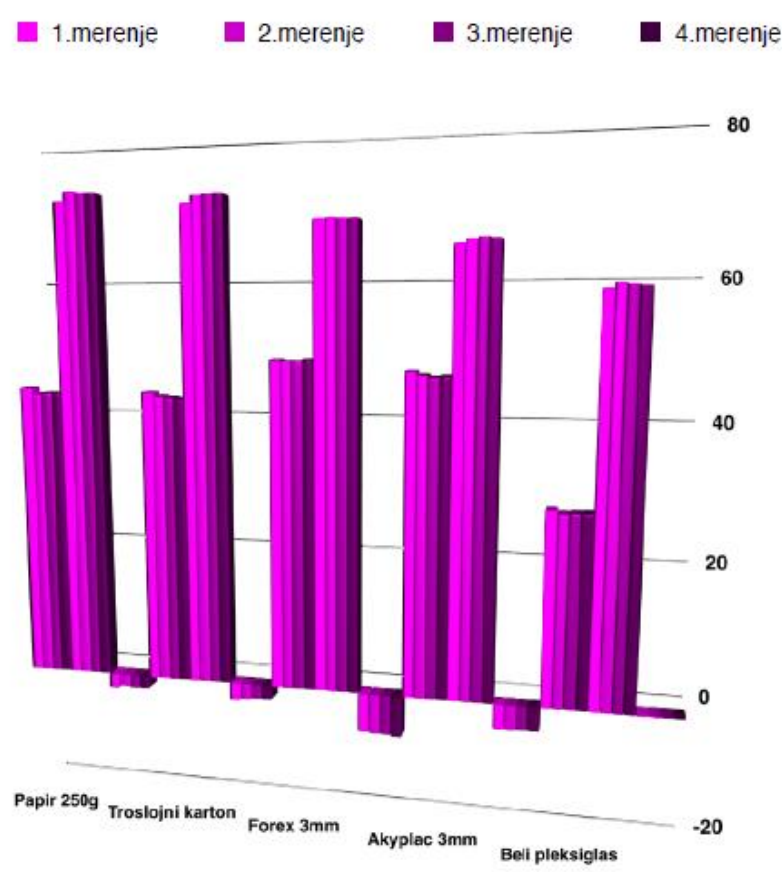

Grafik 6. Prikaz CIE Lab srednje vrednosti za magentu na mašini HP Latex R2000
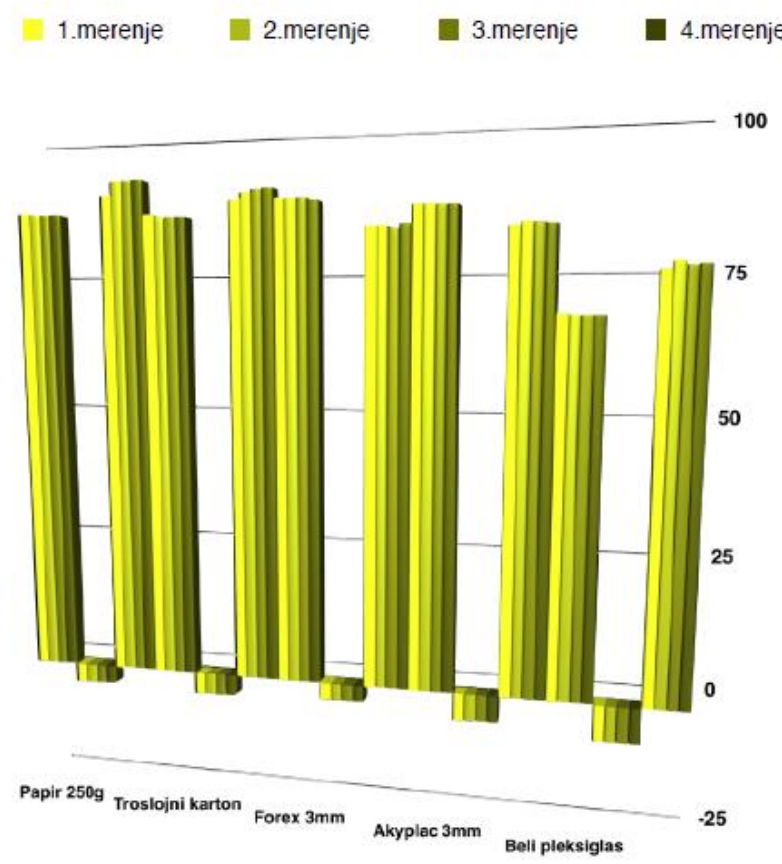

Grafik 7. Prikaz CIE Lab srednje vrednosti za žutu na mašini HP Latex R2000 


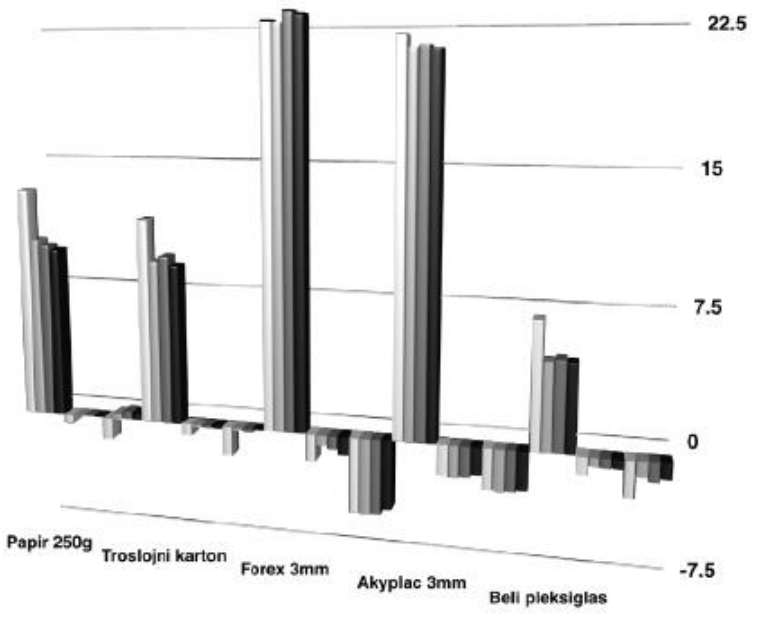

Grafik 8. Prikaz CIE Lab srednje vrednosti za crnu na mašini HP Latex R2000

Prilikom upoređivanja razlika u boji na materijalu Forex 3 mm, može se zaključiti sledeće:

Cijan - Forex $3 \mathrm{~mm}$ odštampan na mašini Durst P10 nakon prvog trljanja nema primetnu razliku, dok je nakon drugog i trećeg trljanja masovna razlika. Kada je u pitanju HP Latex R2000, razlika se ne može primetiti.

Magenta -Forex 3 mm odštampan na mašini Durst P10 ima krupnu razliku, za razliku od Forex-a koji je odštampan na mašini HP Latex R2000, pa se razlika ne može primetiti.

Žuta - Forex 3 mm odštampan na mašini Durst P10 ima srednju razliku. Kada je u pitanju mašina HP Latex R2000, razlika se ne može primetiti.

Crna - Razlika je masivna kada se radi o Forex-u koji je odštampan na mašini Durst P10, a kada je u pitanju mašina HP Latex R2000, razlika je veoma mala.

Prilikom upoređivanja razlika $\mathrm{u}$ boji na materijalu Akyplac 3 mm, može se zaključiti sledeće:

Cijan/Magenta - Akyplac 3 mm odštampan na mašini Durst P10 nakon prvog trljanja ima srednju rayliku, koja je uočljiva golim okom, dok je na mašini HP Latex R2000, razlika neprimetna.

Žuta - Akyplac 3 mm odštampan na mašini Durst P10 nakon prvog i drugog trljanja ima krupnu razliku, dok nakon trećeg trljanja ima masivnu razliku. Kada je u pitanju materijal Akyplac $3 \mathrm{~mm}$ odštampan na mašini HP Latex R2000, razlika se ne može primetiti.

Crna - Razlika je baš masivna kada se radi o Akyplac-u koji je odštampan na mašini Durst P10, a kada je u pitanju mašina HP Latex R2000, razlika je neprimetna.
Prilikom upoređivanja razlika u boji na materijalu beli pleksiglas, može se zaključiti sledeće:

Cijan- Beli pleksiglas nema vidljivu razliku u oba slučaja. Magenta - Nakon prvog trljanja, Beli pleksiglas odštampan na mašini Durst P10 ima veoma malu razliku, dok nakon ostalih trljanja ima srednju razliku. Kada je $\mathrm{u}$ pitanju mašina HP Latex R2000, nema vidljivih razlika.

Žuta - Beli pleksiglas odštampan na mašini Durst P10 nakon prvog i drugog trljanja nema vidljivu razliku, dok nakon trećeg trljanja ima srednju razliku. Kada je u pitanju materijal Beli pleksglas odštampan na mašini HP Latex R2000, razlika se ne može primetiti.

Crna - Razlika je baš neprimetna nakon prvog trljanja kada se radi o Belom pleksiglasu koji je odštampan na mašini Durst P10, dok je nakon ostalih trljanja razlika primetna golim okom. Beli pleksiglas odštampan na mašini HP Latex R2000, razlika je veoma mala.

\section{ZAKLJUČAK}

Kao što je napomenuto, kontrolisanje dobijenih otisaka je najbitnije u celom štamparskom procesu, zaista dobio poželjan kvalitet, bitno je posedovati što bolje mašine, uređaje, materijale, tonere, boje. Kvalitetna štampa jeste pravilno prenošenje otisaka na materijal i izbegavanje grešaka, zato se preporučuje korišćenje mernih instrumenata u grafičkoj industriji. Pridržavanjem ovih zahteva, sa sigurnošću se dobijaju tačni rezultati i traženi kvalitet.

U ovom radu kontrolisana je postojanost odštampanih uzoraka na proces trljanja, kao i dobijene vrednosti za razliku boje prilikom izlaganja uzoraka procesu trljanja

Prilikom analiziranja dobijenih rezultata veća odstupanja se zapažaju na materijalima koji su odštampani na mašini Durst P10, nego na mašini HP Latex R2000. U suštini, ovakvi rezultati su i očekivani, $\mathrm{s}$ obzirom da je mašina HP Latex R2000, novija (mlađa) u odnosu na mašinu Durst P10. Vizuelnim prikazom materijala, koji su bili podložni određenom broju ciklusa trljanja, najjednostavnije se može zapaziti razlika kada se upoređuju ove dve mašine. Na mašini HP Latex R2000 gotovo ne dolazi do skidanja boje na čak tri od pet materijala, što pokazuje koliki kvalitet zaista poseduje ova mašina.

\section{LITERATURA}

[1] Novaković D., Kašiković N. (2013), Digitalna štampa, FTN izdavaštvo, Novi Sad.

[2] Oxford Web Studio, (2018), Digitalna štampa [Online] https://www.oxfordwebstudio.com/da-liznate/sta-je-digitalna-stampa.html (pristupljeno u oktobru 2018.)

\section{Adresa za kontakt:}

MSc Maja Đukić, maja94djukic@gmail.com

Dr Nemanja Kašiković, knemanja@uns.ac.rs

MSc Rastko Milošević, rastko.m@uns.ac.rs 